\title{
B cell activating factor (BAFF) and platelet activating factor (PAF) could both be markers of non-lgE-mediated reactions
}

\author{
G Piuri $^{1 *}$, J Soriano ${ }^{2}$, MC Speciani ${ }^{1}$, AF Speciani ${ }^{3}$ \\ From Food Allergy and Anaphylaxis Meeting (FAAM 2013) \\ Nice, France. 7-9 February 2013
}

\section{Background}

$B$ cell activating factor (BAFF) is a member of the tumor necrosis factor superfamily and an important regulator of peripheral B cell survival, maturation and immunoglobulin class-switch recombination. Many studies suggest that BAFF might be a new mediating mechanism in foodrelated inflammation. Higher levels in non-atopic compared with atopic patients, and no correlation between BAFF and IgE, suggest that BAFF might be particularly involved in non-IgE-mediated reactions [1]. According to Finkelman there are 2 pathways of systemic anaphylaxis: antigens can cause systemic anaphylaxis in mice through the classic pathway by cross-linking IgE bound to mast cell FceRI, stimulating histamine and PAF release, or the alternative pathway by forming complexes with IgG that cross-link macrophage Fc $\gamma$ RIII, stimulating only PAF release [2]. The aim of this study is to evaluate the correlation between BAFF and PAF in non-atopic subjects.

\section{Methods}

We measured the concentration of BAFF $(\mathrm{ng} / \mathrm{ml})$ and PAF (ng/l) in the serum of 64 patients ( 45 females and 18 males, age $44.94 \pm 8.51$ ). All tested subjects did not have IgE-mediated allergies.

\section{Results}

There is statistical evidence of correlation between BAFF and PAF based on the results of a Kendall correlation test $(p<0.0001)$. We explored also the relationship between BAFF/PAF and age and sex of patients. Since both BAFF and PAF are bimodal, we decided to dichotomize them based on biologically relevant thresholds ( $\geqq 2 \mathrm{ng} / \mathrm{ml}$, and $\geqq 7 \mathrm{ng} / \mathrm{l}$, respectively). For both outcomes, we fit a logistic regression and identified age as a significant predictor for each $(\mathrm{p}<0.005)$. In particular for every yearly increase in age, the log odds of having BAFF and PAF over the thresholds is decreased by 0.15 and 0.20 , respectively.

\section{Conclusion}

The second pathway of anaphylaxis requires IgG antibodies, macrophages, Fc $\gamma$ RIII and PAF (but not histamine, serotonin, or leukotriens). The highly significant correlation between BAFF and PAF in non-atopic patients supports the possibility that BAFF is involved in non-IgE-mediated allergic reactions. BAFF is probably one of the cornerstones of the alternative pathway of allergy.

\section{Disclosure of interest}

None declared.

\section{Author details}

${ }^{1}$ SMA srl, Milan, Italy. ${ }^{2}$ Department of Statistical Science, Duke University, Durham, NC, USA. ${ }^{3}$ Food Allergy Department, GEK srl, Milan, Italy.

Published: 25 July 2013

\section{References}

1. Lied GA, Lillestøl K, Valeur J, Berstad A: Intestinal B cell-activating factor: an indicator of non-lgE-mediated hypersensitivity reactions to food? Aliment Pharmacol Ther 2010, 32(1):66-73.

2. Finkelman FD: Anaphylaxis: lessons from mouse models. J Allergy Clin Immunol 2007, 120(3):506-15.

doi:10.1186/2045-7022-3-S3-O5

Cite this article as: Piuri et al:: B cell activating factor (BAFF) and platelet activating factor (PAF) could both be markers of non-lgE-mediated reactions. Clinical and Translational Allergy 2013 3(Suppl 3):05. 